\title{
Jnteração, Escrita e Metaconsciência na Formação Inicial de Professores
}

\author{
Renilson José MENEGASSI \\ Universidade Estadual de Maringá
}

Resumo: Discutem-se as relações do professor com a escrita, em sua formação inicial, a partir de intervenções diretas conduzidas pela perspectiva sócio-interacionista de linguagem. As marcas de alterações apresentadas nos exemplos escritos demonstram como o aluno interage com o texto, construindo uma metaconsciência sobre o processo de escrita, conhecendo a si como produtor e o 'outro' como interlocutor de seu texto. Essa metaescrita se internalizou a partir da alteração da concepção de escrita no aluno, a partir das noções de revisão e reescrita no processo de produção de textos, evidenciando-se o desenvolvimento da metaconsciência na escrita a partir da concepção de escrita como trabalho.

Palavras-chave: escrita; interação; metaconsciência; formação de professores.

\begin{abstract}
Teachers' relationship and writing in their initial training are discussed from immediate interventions based on the language's social and interactional point of view. Analysis of text versions shows that students undertake constructive interactions when writing their texts which in turn lead them towards a metacognitive improvement and, consequently, towards an embodiment of interactional strategies. The development of metaconscience in writing is deduced from the idea that writing is an assignment.
\end{abstract}

Keywords: writing; interaction; metaconscience; teachers' training.

Resumen: Se lleva a cabo un debate sobre las relaciones del profesor con la escritura, en su formación inicial, a partir de intervenciones directas conducidas por la perspectiva socio-interaccionista del lenguaje. Los análisis de versiones de textos escritos enseñan que el alumno universitario realiza interacciones constructivas en sus textos, y eso lo lleva a mejorar de la metacognición y, como consecuencia, la 
incorporación de estrategias de interacción, teniéndose la evidencia del desarrollo de la metaconsciencia en la escritura desde la concepción de la escritura como trabajo.

Palabras-clave: escritura; interacción; metaconsciencia; formación inicial.

\section{Introdução}

Este artigo apresenta uma das fases do projeto "A escrita e o professor: interações no ensino e aprendizagem de línguas", desenvolvido no Grupo de Pesquisa "Interação e escrita no ensino e aprendizagem" (UEM/CNPq), que investiga as relações do professor, em formação inicial, com a escrita, no processo de sua graduação no curso de Letras. A partir de intervenções nos anos de sua preparação, constroem-se, desenvolvem-se e internalizam-se, no acadêmico, procedimentos de escrita que o levam a interações com seu próprio texto, via desenvolvimento metacognitivo de estratégias textuais e discursivas que caracterizam um processo de metaconsciência no produtor de textos. As análises de versões de textos produzidos, durante os anos de 2002 a 2004, demonstram que o aluno realiza interações construtivas nos seus textos, gradativamente, com a mediação do professor, que o leva ao aprimoramento da metaconsciência e, conseqüentemente, à incorporação de estratégias de interação e à alteração da concepção de escrita. Assim, discutem-se as características dessa interação com a escrita, a partir do relato e das análises dos textos produzidos no primeiro ano da graduação, em 2002, para comprovar-se o desenvolvimento da metaconsciência na escrita a partir da concepção de escrita como trabalho.

\section{Interação, Escrita e Metacognição}

O conceito de interação utilizado na pesquisa é o proposto por Bakhtin (1988), que pressupõe um conjunto de trocas efetuadas pelos interlocutores em um contexto particular. Assim, definem-se: a) interlocutores: o aluno, o seu texto produzido, com mediação do professor; b) trocas efetuadas: as alterações no texto do aluno, a partir do desenvolvimento de procedimentos metacognitivos, empregandose as etapas de revisão e reescrita dos textos; c) contexto particular: 
construção de artigo científico em aulas da graduação do curso de Letras.

Para que a interação ocorra de maneira satisfatória, na produção de textos escritos, é necessário que o aluno tenha desenvolvido, ou esteja desenvolvendo, estratégias metacognitivas. A metacognição refere-se ao conhecimento, à consciência, à monitoração e ao controle dos processos cognitivos; é uma manipulação consciente das atividades cognitivas (BAKER; BROWN, 1984a, 1984b; BROWN, 1980; HARRIS; SIPAY, 1985). Para tanto, são utilizados certos procedimentos metacognitivos, que, nas palavras de Oliveira (1995, 152-153), são:

[...] as operações deliberadas do sujeito sobre suas próprias ações intelectuais. Esses são procedimentos que indicam consciência do sujeito a respeito de seus processos de pensamento, a qual lhe permite descrever e explicar esses processos a outras pessoas; envolvem, também, uma busca intencional de estratégias adequadas a cada tarefa específica a partir da consciência de que há diversas regras e princípios possíveis de serem utilizados na solução de problemas.

Nesse sentido, a metacognição envolve dois componentes:

uma consciência sobre quais habilidades, estratégias e recursos são necessários para o desempenho efetivo de uma tarefa; e a capacidade para utilizar os mecanismos auto-reguladores para assegurar a finalização exitosa de uma tarefa, tais como checar, planejar, avaliar, testar, revisar e corrigir. (BAKER; BROWN, 1984a, p. 22)

Os procedimentos conscientes, utilizados pelo indivíduo, permitem determinar e ajustar as estratégias de pensar e aprender, específicas no caso da produção escrita. A metacognição responde à capacidade que possui uma pessoa para controlar e assumir sua própria aprendizagem. Para tanto, quatro implicações ocorrem para a aprendizagem do indivíduo (GARCIA; RIGGS; CAÑIZALES, 2001):

a) adotar uma atitude consciente frente à tarefa de aprendizagem e ao que deve aprender;

b) selecionar, desdobrar e modificar as estratégias, à medida que se envolve na aprendizagem; 
c) conhecer o que significa pensar e aprender efetivamente;

d) internalizar as condições sobre as quais aprende e pensa de maneira efetiva.

A metacognição é o processo de ordem superior que permite ao estudante ser aprendiz contínuo que sabe como, quando, por que e para que utiliza habilidades conscientes na resolução de problemas durante a escrita de seu texto, tomando consciência de suas estratégias metacognitivas. Estas possibilitam a aprendizagem ao guiar os estudantes durante o processo de pensar; também ajuda o aprendiz a seguir um curso de ação inteligente à medida que pensa acerca de um problema, toma decisões, tenta compreender uma situação de produção e recepção de texto.

A aplicação, o domínio e a tenacidade das estratégias demandam tempo, esforço e constância por parte do aprendiz. Este tende a reconhecer o tempo para aprender as estratégias e aplicá-las. Já é conhecida a idéia de que a aprendizagem se incrementa quando se aplicam estratégias metacognitivas, pois a mediação direta de estratégias para pensar é útil e sua aplicação por parte do aprendiz se desenvolve gradualmente, considerando-se a sedimentação temporal necessária a cada indivíduo.

Para Garcia, Riggs \& Cañizales (2001), os estudantes que desenvolvem a metacognição:

a) têm confiança que podem aprender;

b) chegam a conclusões precisas acerca do porquê de uma aprendizagem com êxito;

c) pensam de maneira clara acerca de imprevisões quando falham ao tratar de completar uma tarefa;

d) buscam expandir constantemente seu repertório de estratégias de aprendizagem;

e) desenvolvem estratégias de aprendizagem frente à tarefa a que estão expostos e as ajustam quando necessário;

f) buscam orientações de colegas e professores;

g) ocupam tempo necessário para pensar sobre sua maneira própria de pensar;

h) vêem-se a si próprios como aprendizes e pensadores permanentes. 
Para que a aprendizagem, a partir da metacognição, ocorra em sala de aula, o ensino deve estar centrado no estudante. Um ambiente de aprendizagem centrado no aluno se evidencia ao se observar o nível de motivação e participação ativa manifestada pelos estudantes, assim como o papel do docente como mediador da aprendizagem que espera que seus alunos alcancem êxito ao converterem-se em aprendizes independentes, sempre a partir do pressuposto de que a interação seja a abordagem de trabalho. Nesse sentido, pretende-se fazer do escritor, no caso o aluno-produtor, uma pessoa com estratégias metacognitivas desenvolvidas, ou seja, um indivíduo consciente de seus processos cognitivos e com capacidade para regular as operações mentais próprias da escrita. Para tanto, para que as condições propícias se estabeleçam, é necessário que o aluno tenha um domínio suficiente das operações da escrita e um bom nível de raciocínio, como é caso dos acadêmicos investigados na pesquisa.

Em trabalhos científicos, como os artigos acadêmicos produzidos pelos alunos, a escrita, em geral, e a revisão e a reescrita, em particular, podem representar a utilização de uma boa parcela de tempo e esforço, de maneira consciente, a partir da mediação do docente. No emprego da estratégia de revisão, o escritor mantém uma atitude crítica sobre seu texto, apresentando uma metaconsciência que evidencia sua preocupação com as condições de produção e a recepção do seu texto. Dessa forma, é consciente a procura de ajustes no texto, empregando as operações lingüísticas de acréscimo, substituição, supressão e deslocamento (FABRE, 1986), de forma a ajustar as partes do texto e do discurso que se mostram insatisfatórias ao escritor.

Atualmente, dá-se maior relevância à auto-regulação que exerce um indivíduo sobre as funções relacionadas com a consciência sobre o seu conhecimento. Este enfoque se refere ao funcionamento cognitivo em geral, contudo, ao se referir especificamente à escrita, por extensão, poderia dizer que se está referindo à metaescrita, que é a utilização consciente de estratégias de produção textual.

Burón (1996 apud MORLES, 2003) comenta que rascunhar uma frase, ou um parágrafo, para melhorar o texto, é uma experiência suficientemente conhecida por todos; no entanto, é possível que a muitos não tenha ocorrido pensar que não poderiam realizar a operação de escrever/revisar/reescrever se não tiverem desenvolvida, de alguma maneira, a operacionalização da metaescrita; isto é, se o 
aluno não tiver desenvolvida a capacidade consciente de que seu texto não está adequado às condições de produção. Assim, deduz-se que uma pessoa utilizará sua consciência para escrever quando, ao conduzir este processo, primeiro, se mantenha consciente das etapas que ela mesma compreende; segundo, mantenha-se alerta para monitorar, avaliar e regular a execução de sua escrita.

Ao conduzir a exercitação escrita, é importante ter presente que ela deve buscar a excelência e a tomada de consciência na execução das condutas que exercita, porém, espera-se que, como resultado dessa exercitação, o aluno consiga, eventualmente, manifestar essas condutas de maneira espontânea, automática e oportuna. Isto significa que, como produto final, o escritor deve almejar a internalização, nos moldes vigotskianos, ou cristalização dessas condutas, sempre a partir da aprendizagem do processo de escrita.

A exercitação da metaescrita leva ao desenvolvimento de um estado de alerta durante o processo, com estados de reflexão nas principais etapas: planejamento, execução, revisão e reescrita; assim, uma vez adquirido esse estado, como resultado da prática, em função da sedimentação do conhecimento, o escritor consiga, eventualmente, mantê-lo automático e inconsciente.

\section{Concepção de Escrita}

Toma-se por pressuposto teórico, nesta pesquisa, a concepção de escrita como trabalho, consubstanciada na perspectiva ideológica de Bakhtin (1988) e nos estudos decorrentes, no Brasil. Nesta concepção, o professor torna-se mediador do processo de construção da escrita, sendo esta um ponto de interação entre o aluno e o professor. $\mathrm{O}$ aluno mostra-se sujeito de suas ações escritas, revelando a presença do 'outro' no seu texto a partir da autocorreção que efetua, agindo com, sobre e na linguagem (GERALDI, 1993); usando procedimentos de metaconsciência, como as atividades epilingüísticas, ou seja, é um momento de reflexão própria sobre a linguagem, consciente, em que as expressões lingüísticas passam a ser objeto de trabalho; na realidade, é momento em que o texto revela o autor a si próprio.

O 'outro’ é presente na memória do indivíduo, o que faz o texto escrito ser um ponto de interação, fazendo com que o próprio autor seja leitor de si mesmo, autocorrigindo-se, usando, para tanto, 
procedimentos metacognitivos, interagindo com o texto e com o outro que se faz presente no texto, sempre a partir da mediação do professor.

Nessa concepção, o professore é leitor e co-autor do aluno, mostrando a necessidade de a escrita envolver momentos diferentes, como o planejamento, a execução, a revisão e a reescrita. Estas duas últimas, especialmente, despertam, no aluno, a consciência de que escrever é trabalhar, que as mudanças na escrita não são apenas no aspecto superficial, mas também em sua estrutura interna e discursiva, considerando-se as condições de produção do texto. A partir dessas noções, a escrita é vista como um trabalho consciente, deliberado, planejado, pensado e repensado.

\section{A Pesquisa}

Foi escolhida para a realização da pesquisa interventivalongitudinal uma turma do curso de Letras, da Universidade Estadual de Maringá (UEM), iniciantes na vida acadêmica no ano letivo de 2002. A turma era composta por 40 alunos, com idade média entre 18 e 22 anos. A maioria dos alunos era da região Noroeste do Paraná, trabalhando no período vespertino e alguns no período noturno.

Para a realização do trabalho foram feitos acordos pedagógicos com os professores das disciplinas Lingüística, Língua Portuguesa e Introdução aos Estudos Literários, como maneira de possibilitar uma interface maior entre os conteúdos e a própria produção escrita dos alunos, isto é, os três professores auxiliaram na construção da escrita, ficando o professor de Lingüística responsável pela formulação acadêmica do texto trabalhado: artigo científico, gênero textual muito requisitado na vida acadêmica. Assim, durante todo o ano letivo de 2002, os três professores trocaram experiências no sentido de possibilitar aos alunos o máximo de atividades escritas que envolvessem temas das disciplinas, sempre com a noção de escrita como trabalho, desenvolvendo as noções de metaconsciência e metaescrita.

Uma questão discutida com os alunos foi a quantidade de produções escritas que deveriam efetivar, demonstrando que a qualidade deve se sobrepor à quantidade, isto é, os textos necessariamente precisam de um determinado tempo para ficar prontos, envolvendo para isso as fases do processo de escrita: 
planejamento, execução, revisões e reescritas, o que, invariavelmente, demanda um espaço maior de tempo no bimestre. Dessa forma, as produções ficaram assim distribuídas:

- $1^{\circ}$ bimestre: um artigo escrito a partir de seminário apresentado sobre as características da língua, com no máximo três páginas;

- $2^{\circ}$ bimestre: um artigo escrito envolvendo as teorias sobre as concepções de linguagem e análises de exercícios de livro didático, exemplificando as concepções, com no máximo quinze páginas;

- $3^{\circ}$ bimestre: um artigo escrito envolvendo a teoria da Lingüística Textual, analisando-se uma redação produzida no vestibular da UEM, o mesmo que os alunos realizaram para ingressar, com no máximo 25 páginas.

Os artigos produzidos nos três primeiros bimestres foram mediados a partir da incorporação das noções de planejamento, revisão e reescrita de textos. Para demonstrar a evolução na noção de construção da escrita na graduação, assim como as incorporações das estratégias de revisão e reescrita, que levam ao desenvolvimento da metaescrita, a partir de procedimentos metacognitivos e, conseqüentemente, à interação com o próprio texto, tomam-se como parâmetros de análise excertos dos textos produzidos, como forma de discussão e comprovação da pesquisa. Infelizmente, por questão de espaço, apresentam-se apenas exemplificações das produções escritas de um aluno.

\section{Algumas Escritas: Apontamentos, Alterações e Procedimentos Metacognitivos}

São apresentados três exemplos de escritas, selecionados do artigo produzido no terceiro bimestre por um aluno. A primeira versão apresenta as rasuras, os apontamentos e as anotações que o aluno realizou na produção do texto. A segunda versão é a reescrita da primeira e a terceira, o resultado final do texto.

Exemplo 1:

a) Apontamentos e alterações efetivadas na $1^{a}$ versão: 


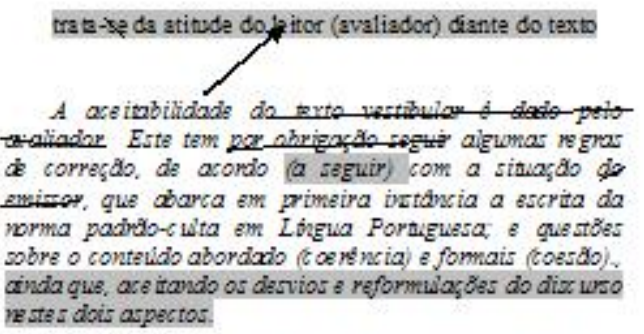

Ester dois aspector:

O texto. quando, ak arjabo as necesridaces deste corretor is a eito Deste modo, podemos afrmar que "Solidariedade e racionalidade para dbinus a fome" wonbeim supriu com essat exigencias e foi ponsentido. resiltando moma boa c lassificasdo.

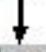
referente a coeréncia, coesảo, relevâncis e possibilidade de vtilizaçäo cominicaçâo)

b) $2^{\mathrm{a}}$ versão:

A aceitabilidade trata da atitude do leitor (avaliador) diante do texto. Este tem algumas regras de correção estabelecidas a seguir, para avaliar a produção do candidato. Talprocedimento abarca em primeira instância a escrita da norma padrão-culta em Lingua Portuguesa, compreendendo sobre o conteúdo abordado, questões de coerência e coesão.

O texto, quando atinge esse objetivo, é aceito pelo corretor. Desse modo, podemos afirmar que "Solidariedade e racionalidade para diminuir a fome" também supriu essas exigências e foi aprovado, resultando numa boa classificação.

c) $3^{\mathrm{a}}$ versão: idêntica à $2^{\mathrm{a}}$ versão.

Nota-se que, pelos apontamentos e observações entre as versões, o aluno empregou três operações lingüísticas na reescrita do texto: substituição, supressão e acréscimo, sendo a primeira a operação mais utilizada.

- Substituição:

O texto, quando, alcançado às necessidades deste corretor é aceito. ( $1^{\mathrm{a}}$ versão)

$O$ texto, quando atinge esse objetivo, é aceito pelo corretor. $\left(2^{\mathrm{a}}\right.$ versão) 
- Supressão:

Este tem por obrigação seguir algumas regras de correção $[\ldots]\left(1^{\mathrm{a}}\right.$ versão)

Este tem algumas regras de correção estabelecidas a seguir [...] (2a versão)

- Acréscimo:

[...] que abarca em primeira instância a escrita da norma padrãoculta $[. .$.$] ( 1^{\mathrm{a}}$ versão)

Tal procedimento abarca em primeira instância a escrita da norma padrão-culta... ( $2^{\mathrm{a}}$ versão)

O aluno busca melhorar o seu texto a partir de substituições que deixam o texto mais fluente, considerando a presença do 'outro' na leitura, demonstrando a preocupação com a escrita e o seu interlocutor, através de um discurso que represente suas idéias de maneira mais adequada ao discurso científico, isto é, direta e objetivamente, como foi solicitado durante a produção do artigo em sala de aula. Nesse momento, o aluno demonstra que a concepção de escrita como trabalho começa a se mostrar através dos apontamentos realizados no excerto exemplificado, que exara um sentido mais adequado ao discurso científico do artigo produzido.

Exemplo 2:

a) Apontamentos e alterações efetivadas na $1^{a}$ versão: 


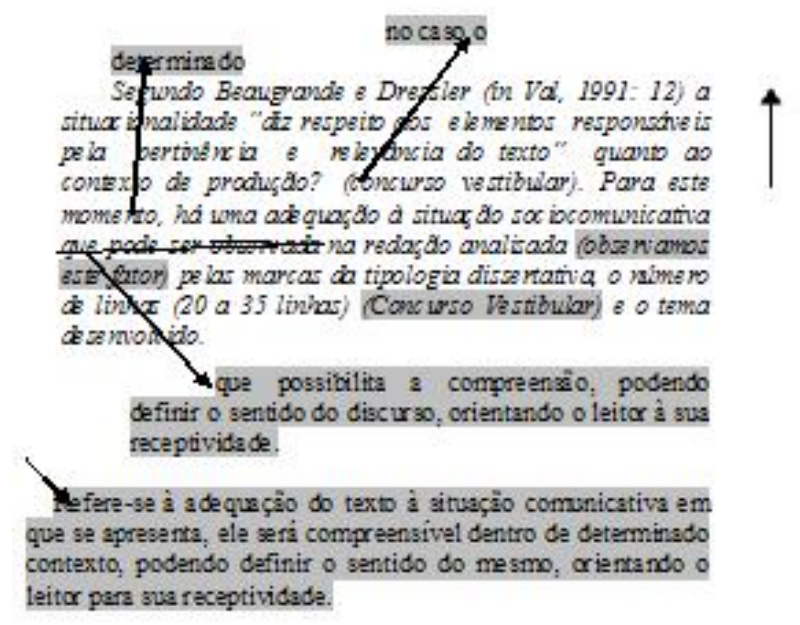

b) $2^{\mathrm{a}}$ versão:

Segundo Beaugrande e Dressler (in VAL, 1991, p. 12) a situacionalidade "diz respeito aos elementos responsáveis pela pertinência e relevância do texto" quanto ao contexto de produção (concurso vestibular). Para este momento determinado, há uma adequação à situação sociocomunicativa, que inclui a tipologia dissertativa, com um número de 20 a 35 linhas e o tema desenvolvido. Isso possibilita a compreensão, podendo definir o sentido do discurso, orientando o leitor para sua receptividade.

c) $3^{\mathrm{a}}$ versão: idêntica à $2^{\mathrm{a}}$ versão.

Nestes excertos, o aluno emprega apenas duas operações lingüísticas: acréscimo e substituição. $\mathrm{Na}$ operação de acréscimo, efetivase um trabalho consciente de escrita, pois são apresentadas três maneiras diferentes de acréscimos de informações, sendo uma delas com deslocamento.

- Acréscimo:

1) empregado na rasura da primeira versão, porém não utilizado na reescrita:

\footnotetext{
[...] quanto ao contexto de produção no caso o (concurso vestibular). ( $1^{\mathrm{a}}$ versão)
} 
[...] quanto ao contexto de produção (concurso vestibular). ( $2^{\mathrm{a}}$ versão);

2) empregado na rasura da primeira versão e na reescrita: Para este momento [...], ( $1^{\text {a }}$ versão)

Para este momento determinado,[...] (2 $2^{\mathrm{a}}$ versão);

3) emprega na rasura da primeira versão num determinado local do parágrafo e desloca a informação acrescida para outro lugar na reescrita:

[...] que possibilita a compreensão, podendo definir o sentido do discurso, orientando o leitor à sua receptividade [...] ( $1^{\text {a }}$ versão inserção apresentada no segundo período)

Isso possibilita a compreensão, podendo definir o sentido do discurso, orientando o leitor para sua receptividade $[. .].\left(2^{\mathrm{a}}\right.$ versão informação acrescida e deslocada para o último período do parágrafo).

Neste segundo exemplo, já são notados indícios da metaconsciência na construção da escrita. Nos apontamentos da primeira versão, observa-se, ao final, a apresentação de uma informação mais longa, em várias linhas, que é resumida acima, para ser incorporada na reescrita como o último período:

- Informação longa, ao final da primeira versão: Refere-se à adequação do texto à situação comunicativa em que se apresenta, ele será compreensivel dentro de determinado contexto, podendo definir o sentido do mesmo, orientando o leitor para sua receptividade.;

- Informação resumida, na primeira versão: que possibilita a compreensão, podendo definir o sentido do discurso, orientando o leitor à sua receptividade.;

- Informação apresentada, na versão reescrita: Isso possibilita a compreensão, podendo definir o sentido do discurso, orientando o leitor para sua receptividade. 
O procedimento metacognitivo revelado pelo aluno demonstra, de acordo com Garcia, Riggs \& Cañizales (2001), uma atitude consciente frente à aprendizagem de construção do texto, selecionando informações necessárias para elucidar ao interlocutor a idéia apresentada, modificando, já na primeira versão, através da reescrita da rasura/acréscimo, o pensar e aprender sobre a tarefa escrita, a partir da seleção, desdobramento e modificação de estratégias necessárias à situação, resolvendo o problema conscientemente. Nota-se que o próprio discurso do aluno leva o leitor à fluência na leitura, o que demonstra as alterações manifestadas.

Exemplo 3:

a) Apontamentos e alterações efetivadas na $1^{a}$ versão:

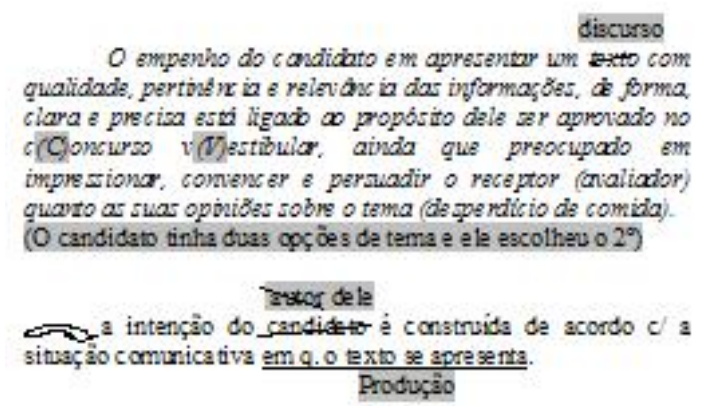

b) $2^{\mathrm{a}}$ versão:

A intenção do candidato é construida de acordo com a situação comunicativa de produção. O seu empenho se faz em apresentar um discurso com qualidade, pertinência e relevância de informações ao tema escolbido, de forma clara e precisa, ligada ao propósito de ele ser aprovado no Concurso Vestibular. Tem ainda a preocupação de impressionar, convencer e persuadir o receptor (avaliador) quanto as suas opiniões sobre o assunto. 
c) $3^{a}$ versão: idêntica à $2^{a}$ versão.

As operações demonstradas no terceiro exemplo restringem-se à substituição e ao acréscimo. Da mesma forma como exemplificado anteriormente, nestes excertos o aluno também apresenta indícios de procedimentos metacognitivos.

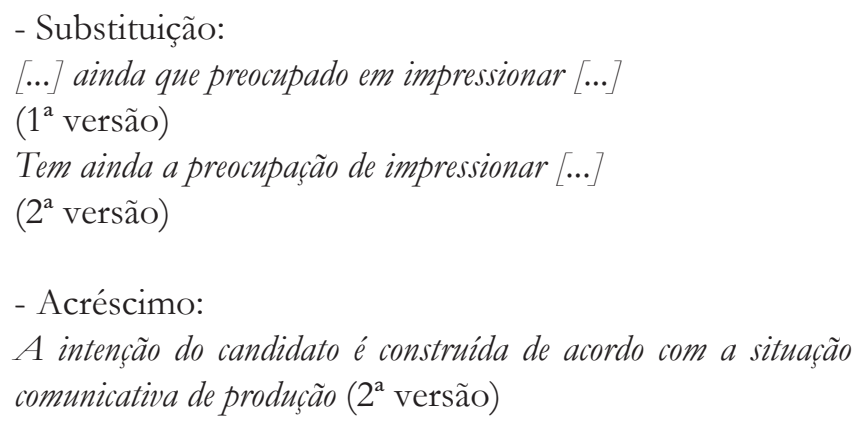

No Exemplo 2, observou-se que o aluno acrescentou informação no último período. No Exemplo 3, o mesmo procedimento ocorre, explicitamente efetivando o uso de estratégia metacognitiva, porém, no início do parágrafo, demonstrando a estratégia discursiva escolhido pelo aluno. Ao final dos apontamentos realizados na primeira versão, encontra-se acréscimo de informações que não está localizado explicitamente em alguma parte do texto, apenas apontado como informação a ser incorporada, dedutível da seta que o acompanha:

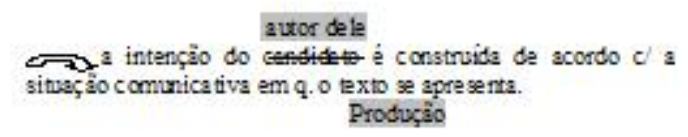

Observa-se, mesmo na apresentação do acréscimo de informação, que já se produz uma reescrita, com a alteração de duas proposições no texto: "candidato" por "autor - dele" (optando-se pela primeira, na $2^{\mathrm{a}}$ versão), "em q. o texto se apresenta" por "Produção". Ao 
chegar nesta fase, o aluno demonstra uma consciência de que seu texto não tem apenas a si ou o outro-professor como únicos interlocutores, apresentando alterações discursivas que evidenciam marcas de construção de seu próprio discurso. Há, neste caso, uma demonstração de preocupação com o 'outro' na construção do texto e de seu discurso, o que marca a incorporação da concepção de escrita como trabalho, em que o texto é uma mediação entre o autor e seu leitor.

Outra questão a destacar é o acréscimo da informação numa posição em que o leitor possa entender melhor o texto que se apresenta, marcando uma estratégia discursiva própria desse aluno. Assim, o aluno, nos exemplos 2 e 3, mostra uma preocupação com seu interlocutor, corroborando o que já de analisou até o momento.

\section{Conclusão}

O trabalho realizado com os alunos demonstrou que houve o desenvolvimento e a ampliação da sua interação com o texto, a partir da mediação do professor, que deixa de ser visto como único interlocutor, passando a colaborador no processo de construção do texto escrito. Dessa maneira, o texto escrito e o seu processo de construção passam a fazer parte da interação no processo de ensino e aprendizagem da sala de aula, fator relevante na formação inicial do professor, que aprende a pensar sobre a construção de seu texto, juntamente com as observações do mediador, num processo consciente de ambas as partes. Essa postura levou à alteração da concepção de escrita estabelecida pela escola tradicional, construindose a concepção de escrita como trabalho. Nesse sentido, houve poucas intervenções do professor e mais alterações do próprio aluno, criandose, assim, uma interação do aluno com seu próprio texto, objetivo maior do trabalho.

Essas interações, na verdade, são frutos de uma relação maior de interlocução, em que os professores das disciplinas envolvidas na pesquisa e, especificamente, o professor mediador da produção do artigo, posicionaram-se como atores da interação. Nesse sentido, é evidente que a conscientização do processo de escrita do aluno foi desenvolvida a partir dessa relação interativa entre os professores e o próprio aluno. É certo, também, que sozinho ele não desenvolveria tal consciência em pouco tempo, como observado na pesquisa. Desta 
forma, os processos interacionais envolvidos puderam ser observados sob três perspectivas: a) do aluno, enquanto produtor efetivo do texto; b) dos professores das disciplinas envolvidas, enquanto docentes que subsidiavam os alunos com exercícios de reflexão e produção de conhecimentos, no período de formação docente; c) do professor mediador, enquanto pólo que envolvia o aluno na sua produção escrita, relacionando-a aos conteúdos angariados nas disciplinas, como também no desenvolvimento dos processos de revisão e reescrita dos textos, a partir da visão de interlocução, em que o outro-professor assume o papel de co-produtor, ambos visando a 'outro' leitor, alvo principal do discurso.

Nesse sentido, as marcas de alterações apresentadas nos exemplos demonstram como o aluno interage com o texto, construindo uma metaconsciência sobre o processo de escrita, conhecendo a si como produtor e o 'outro' como interlocutor de seu texto, a partir da visão de que o 'outro-professor' o auxilia durante o processo. Essa metaescrita se internalizou a partir da alteração da concepção de escrita no aluno, a partir das noções de revisão e reescrita no processo de produção de textos.

Além disso, os resultados, a partir dos pressupostos de Garcia, Riggs \& Cañizales (2001), mostraram que o aluno

a) adotou uma atitude consciente frente à tarefa de construir seu texto, à tarefa de aprendizagem e ao que deve aprender nesse processo;

b) selecionou, desdobrou e modificou as estratégias empregadas na revisão e reescrita do texto, à medida que se envolvia na aprendizagem de sua escrita;

c) passou a conhecer o que significa pensar e aprender efetivamente sobre sua própria escrita, desenvolvendo, assim, estratégias metacognitivas que o levaram à consciência do processo, chegando à metaconsciência na escrita (metaescrita);

d) internalizou as condições sobre as quais aprende e pensa de maneira efetiva, passando a considerar a escrita como trabalho, não como conseqüência ou dom/inspiração, como a escola tradicional propõe.

Os resultados desta fase da pesquisa já apontam para uma alteração nos procedimentos e abordagens no trato com a escrita com 
os professores em formação inicial. Ao longo do processo de investigação, novos registros escritos poderão consolidar os indícios aqui levantados.

\section{Referências Bibliográficas}

BAKER, L.; BROWN, A. L. Cognitive monitoring in reading. In: FLOOD, J. (Ed.). Understanding reading comprehension: cognition, language and the structure of prose. Newark, Delaware: IRA, 1984a. p. 21-44.

Metacognitive skills and reading. In: PEARSON, D. (Ed.) Handbook of reading research. New York: Longman, 1984b. p. 353-394.

BAKHTIN, M. Marxismo e filosofia da linguagem. 4. ed. São Paulo: Hucitec, 1988.

BROWN, A. L. Metacognitive development and reading. In: SPIRO, R. J. (Ed.). Theoretical issues in reading comprehension. Hillsdale: Lawrence Erlbaum, 1980. p. 453-481.

FABRE, C. Des variantes de brouillon au cours préparatoire. Études de Linguistique Appliquée, v. 62, p. 59-79, Avril-Juin, 1986.

GARCIA, A. G.; RIGGS, E.; CAÑIZALES, R. Metacognición: punto de ignición del lector estratégico. Lectura y Vida, 3, p. 28-35, set. 2001.

GERALDI, J.W. Portos de passagem. São Paulo: Martins Fontes, 1993.

HARRIS, A. J.; SIPAY, E. R. How to increase reading ability: a guide to development and remedial methods. 8. ed. New York: Longman, 1985.

MORLES, A. Desarrollo de habiliddes para la escritura eficiente. Lectura y Vida, 3, p.28-35, set., 2003. 
OLIVEIRA, M. K. Letramento, cultura e modalidades de pensamento. In: KLEIMAN, A. B. (Org.). Os significados do letramento: uma nova perspectiva sobre a prática social da escrita. Campinas: Mercado de Letras, 1995. p. 147-60. 